BMJ Open

Diabetes

Research

\& Care

\section{Disparities in recommended preventive care usage among persons living with diabetes in the Appalachian region}

To cite: Sohn M-W, Kang $\mathrm{H}$ Park JS, et al. Disparities in recommended preventive care usage among persons living with diabetes in the Appalachian region. BMJ Open Diabetes Research and Care 2016;4: 000284 . doi:10.1136/bmjdrc-2016000284

- Additional material is available. To view please visit the journal online (http://dx. doi.org/10.1136/bmjdrc2016-000284).

Received 9 June 2016 Revised 26 August 2016 Accepted 29 August 2016

CrossMark

For numbered affiliations see end of article.

Correspondence to Dr Jennifer Mason Lobo; jem4yb@virginia.edu

\section{ABSTRACT}

Objective: To examine disparities in the receipt of preventive care recommended by the American Diabetes Association (ADA) between Appalachian and non-Appalachian counties and within Appalachian counties.

Research design and methods: Behavioral Risk Factor Surveillance System (BRFSS) data for 20082010 were used to identify individuals with diabetes and their preventive care usage. Each Appalachian respondent county of residence was categorised into one of the five economic levels: distressed, at-risk, transitional, competitive and attainment counties. Competitive and attainment counties were combined and designated as competitive counties. We used logistic regressions to compare receipt of ADA preventive care recommendations by county economic level, adjusting for respondent demographic, socioeconomic, health and access-to-care factors.

Results: Compared to the most affluent (competitive) counties, less affluent (distressed and at-risk) counties demonstrated equivalent or higher rates of self-care practices such as daily blood glucose monitoring and daily foot checks. But they showed $40-50 \%$ lower uptake of annual foot and eye examinations and $30 \%$ lower uptake of diabetes education and pneumococcal vaccinations compared to competitive counties. After adjusting for demographic factors, significant disparities still existed in the uptake of annual foot examinations, annual eye examinations, 2 or more A1C tests per year and pneumococcal vaccinations in distressed and at-risk counties compared to competitive counties. Appalachian counties as a whole were similar to non-Appalachian counties in the uptake of all recommendations with the absolute differences of $\leq 3 \%$.

Conclusions: Our results show that there are significant disparities in the uptake of many recommended preventive services between less and more affluent counties in the Appalachian region.

\section{INTRODUCTION}

Diabetes currently affects over $9 \%$ of US adults and $26 \%$ of the elderly population aged 65 years or older. ${ }^{1}$ The economic costs of diabetes are huge. Thirteen per cent of

\section{Key messages}

- Significant disparities by county economic level existed in the uptake of preventive care services that require visits to health professionals in the Appalachian region.

- However, the least affluent counties were not different from or often exceeded the most affluent counties in terms of self-care practices such as daily blood glucose check or daily foot check.

- After demographic, economic, and access-tocare factors were adjusted, disparities disappeared in all recommended care except for the uptake of annual foot exams.

total national healthcare expenditures ${ }^{2}$ and over $30 \%$ of Medicare expenditures are currently spent on persons with diabetes. ${ }^{3}$

Diabetes increases the risk of developing macro- and microvascular complications, which lead to substantial disease and economic burden. ${ }^{4-7}$ In particular, the elderly are disproportionately affected by diabetic complications. Prevention of these complications is an important concern for the Centers for Medicare and Medicaid Services (CMS) since treatment for these complications account for a large proportion of diabetes-related medical expenditures. ${ }^{8-11}$ According to a study by the American Diabetes Association (ADA), only about 14\% of all healthcare expenditures attributed to diabetes were spent to treat diabetes itself and the remaining $86 \%$ were spent to treat diabetic complications. ${ }^{2}$ A simulation study by Zhuo et $a l^{10}$ attributed $48-64 \%$ of the lifetime medical costs of diabetes to diabetic complications, which may underestimate the true costs when considering that costs for foot ulceration and amputations were not included in Zhuo's estimates.

It has been shown that the incidence and progression of diabetic complications ${ }^{12}$ and their associated costs can be reduced by preventive care. $^{13}{ }^{14}$ For this reason, the ADA recommends annual preventive care, 
including at least two A1c tests, a foot examination, an eye examination and cholesterol tests. ${ }^{12}$ Preventive care is also a priority in the national health policy; Healthy People 2020 includes increased use of preventive services for persons with diabetes as its objectives (D4D14). A recent study showed that use of these services had been increasing steadily in 2001-2010. ${ }^{15}$ Despite these encouraging trends, there is a concern that the uptake of diabetes preventive care is suboptimal, especially in underserved populations and rural areas. ${ }^{16-18}$

Health disparities within the Appalachian region are a significant public health concern. ${ }^{19-22}$ For example, this region is known to have disproportionately high rates of diabetes and other chronic diseases. ${ }^{20}{ }^{23}$ Almost $80 \%$ of the less affluent counties in the region were recently identified as part of the 'diabetes belt', ${ }^{24}$ defined as having diabetes prevalence $\geq 11 \%$ compared to $9 \%$ in the rest of the country. With poor access to care, high poverty rates and poor education, less affluent counties in the region may be at a higher risk of not receiving care consistent with the ADA recommendations. A better understanding of health disparities in the Appalachian region with respect to diabetes can provide insights into more effective management of diabetes and prevention of diabetic complications for residents in this region.

Our objective in this study was to examine whether there are disparities in the uptake of diabetes preventive care between the Appalachian region and the rest of the country and, within the Appalachian region, between county economic levels designated by the Appalachian Regional Commission for economic and health planning.

\section{RESEARCH DESIGN AND METHODS}

Data sources and study sample

The Behavioral Risk Factor Surveillance System (BRFSS) is an annual random-digit dialing telephone survey of $\mathrm{U}$. S. adults about their health-related risk behaviours, chronic conditions and preventive care usage. We used BRFSS data for 2008-2010, the latest 3 years when the 'Diabetes' module was administered to all states, to identify all respondents who answered 'Yes' to the question 'Have you ever been told by a doctor that you have diabetes?' Respondents who were not sure, or who refused to answer this question, were excluded from analysis $(<0.1 \%$ of all respondents). Respondents with missing age or education $(0.8 \%$ and $0.3 \%$ of respondents with diabetes, respectively) were too few to be meaningfully analysed in a separate 'missing' category and were excluded. We further excluded respondents who did not report county of residence because it is the key variable to determine the county economic level.

\section{ADA guideline-recommended preventive services}

We obtained all measures from the BRFSS surveys that were consistent with the ADA standards of medical care. ${ }^{12}$ They included a minimum of two A1c tests in the past 12 months, daily blood glucose self-test, annual foot examinations, daily foot self-check, annual eye examinations, diabetes self-management education, annual influenza vaccination and pneumococcal vaccination. These are the same nine preventive care practices tracked by the Centers for Disease Control and Prevention (CDC) ${ }^{25}$ For all of these practices other than Alc tests, respondents with 'Don't Know/Not Sure' answers were excluded from the analysis. For A1c tests, we coded 'Never heard of A1c test' and 'Don't know/Not sure' answers as evidence of not receiving care consistent with ADA guidelines, because over $12 \%$ of all persons with diabetes responded with either of these answers and their distribution across the county economic levels was not even, suggesting that health literacy might have affected responses. The parameterisation of these measures using BRFSS survey questions is summarised in online supplementary table A1. All preventive practices were included in the BRFSS in all 3 years, except for annual influenza vaccination that was asked only in 2010 .

\section{County economic status}

The Appalachian Regional Commission (ARC), a federal agency composed of the governors of the 13 Appalachian states and a federal co-chair appointed by the President, publishes the county economic level to identify and monitor the economic status of Appalachian counties. Each county in the Appalachian region is classified into one of the five economic levels, based on its position in the national ranking in three economic indicators, including 3-year unemployment rate, per capita market income and poverty rate. Distressed counties rank in the lowest $10 \%$, at-risk counties in the lowest $10-25 \%$, transitional counties in the 25-75\%, competitive counties in the 75-90\% and attainment counties in the top $10 \%$. We used the classification for 2013 because it best reflects the economic status of this region for the study period. ${ }^{26}$ Because there were only three attainment counties sampled in the BRFSS during the study period, we decided to combine them with competitive counties and designate them as competitive counties in this study. Residents living outside the Appalachian region were placed into the fifth category (non-Appalachian).

\section{Covariates}

All covariates that can potentially affect patients' receipt of guideline recommended services were grouped into demographic, socioeconomic, health and access-to-care factors. Demographic factors included age, sex, race/ ethnicity and marital status. Marital status indicates whether the patient lives with someone who can provide support for diabetes care.

For socioeconomic factors, we included annual household income, education and employment status. 
Health factors included body mass index, smoking, exercise, disability, previous heart attack or stroke, coronary heart disease and diabetes severity indicated by current insulin use and diabetes duration. Diabetes duration was computed based on age at diabetes diagnosis and age at the survey. Exercise indicates whether a person was engaged in any physical activities or exercises in the past 30 days. Disability indicates whether a person had any activity limitations due to physical, mental or emotional problems.

Finally, access-to-care factors included whether the respondent had health insurance, whether the respondent had a personal doctor, whether the respondent perceives cost as a barrier to medical care and whether the respondent had a routine medical check-up in the past 1 year. From the 2014 Area Health Resources File, we also obtained indicators of availability of medical services in county, including the number of medical doctors, podiatrists, ophthalmologists and optometrists, the number of federally qualified health centres and the health professional shortage area designation.

\section{Statistical analysis}

To account for the complex sampling design, we conducted all statistical analyses using Survey suite of programs in Stata SE V.14. We used appropriate subpopulation methods to correctly calculate SEs of the estimates for exclusions as well as stratified analyses. ${ }^{27}$

Absolute rates were compared across county groups using weighted Pearson $\chi^{2}$ tests in bivariate analyses. Relative differences were computed using multivariable logistic regression with the competitive counties as the reference group. We estimated a series of regression models to determine how each group of covariates affects disparities across county economic levels in preventive care practices. For example, 'gross' relative differences were estimated using unadjusted models and we added demographic factors, socioeconomic factors, individual health factors and access-to-care factors to the unadjusted model one group at a time. We used the competitive Appalachian counties as the reference group, because they were the most affluent counties and our bivariate analyses showed that they generally had the highest receipt of guideline-recommended practices.

Because Medicare provided coverage for diabetesrelated preventive services since $2005,{ }^{28}$ financial incentives for patients to use these services may be different by Medicare eligibility. We performed stratified analyses of disparities by county economic levels for persons with ages $\geq 65$ and those $<65$ years.

\section{RESULTS}

After exclusion, of about 1.3 million respondents to the 2008-2010 BRFSS surveys, we found that 138832 respondents had diabetes, which represented $9.0 \%$ of the US adults aged $\geq 18$ years. There were significant differences between county economic levels in all respondent characteristics we considered in this study (table 1). Striking disparities are found in socioeconomic status and access to care factors. While $42 \%$ in distressed counties had annual household income $<\$ 20,000$, only $18 \%$ did so in competitive counties. In educational attainment, $30 \%$ of patients in distressed counties did not complete high school compared to only $9 \%$ in competitive counties. In distressed counties, $24 \%$ perceived cost as a barrier to medical care compared to $11 \%$ in competitive counties. Of respondents with diabetes in distressed counties, $57 \%$ and $76 \%$ resided in counties without any physicians and any podiatrists in their county, respectively, compared to $6.4 \%$ and $2.9 \%$ of those in competitive counties.

Table 2 presents weighted percentages of respondents who received services consistent with ADA recommendations for diabetes-related preventive care. Nationally, adherence to recommended services was the best for annual doctor visits at $88.0 \%$ of all respondents with diabetes and poorest for pneumococcal vaccination at $53.7 \%$. Appalachian counties as a whole were similar to non-Appalachian counties in all nine recommendations with the absolute differences $\leq 3 \%$ for all but daily foot check in which Appalachian counties showed better uptake than non-Appalachian counties $(\mathrm{p}<0.001)$.

Disparities were more pronounced within Appalachia. Compared to competitive counties, distressed counties showed significantly lower uptake in annual foot examination $(68.0 \%$ vs $77.8 \%)$, annual eye examination $(59.6 \%$ vs $73.7 \%)$ and self-management education $(46.0 \%$ vs $54.6 \%)(\mathrm{p}<0.001$, all comparisons). On the other hand, distressed counties exceeded competitive counties in self-care practices such as daily blood glucose self-test $(71.2 \%$ vs $63.9 \%)$ and daily foot check $(72.5 \%$ vs $69.7 \%)$. Similarly, at-risk counties also showed better receipt of preventive care recommendations than competitive counties in daily blood glucose self-test $(64.2 \%$ vs $63.9 \%)$ and daily foot check $(76.4 \%$ vs $69.7 \%)$.

Table 3 presents unadjusted and adjusted ORs of uptake consistent with nine guideline recommendations for each county economic level using competitive counties as the reference group. In unadjusted analyses, patients in distressed counties were almost $40 \%$ more likely to perform daily blood glucose check $(\mathrm{OR}=1.40$; $95 \%$ CI 1.10 to 1.78 ) and those in at-risk counties were $41 \%$ more likely to perform daily foot check $(\mathrm{OR}=1.41$; 95\% CI, 1.11 to 1.79 ) compared to patients in competitive counties. Non-Appalachian counties were not different from competitive counties.

Significant disparities were also found in adherence to recommendations that require visits to health professionals such as Alc tests, foot and eye examinations. Most notably, patients in distressed and at-risk counties were $40-50 \%$ lower in the uptake of annual foot and eye examinations and about $30 \%$ lower in the uptake of diabetes self-management education and pneumococcal vaccination. When demographic factors such as age, 
Table 1 Demographic, socioeconomic and access-to-care characteristics for respondents with diabetes by county economic level, 2008-2010*

\begin{tabular}{|c|c|c|c|c|c|c|}
\hline Respondent characteristics & Distressed & At-risk & Transitional & Competitive & Non-Appalachian & p Value \\
\hline \multicolumn{7}{|l|}{ Demographic factors } \\
\hline Age in years & 47.2 & 47.6 & 48.2 & 49.1 & 46.7 & $<0.001$ \\
\hline Male & $47.5 \%$ & $47.2 \%$ & $49.3 \%$ & $52.4 \%$ & $51.1 \%$ & $<0.001$ \\
\hline \multicolumn{7}{|l|}{ Race/ethnicity } \\
\hline NH White & $83.2 \%$ & $86.3 \%$ & $82.3 \%$ & $78.9 \%$ & $60.4 \%$ & \multirow[t]{4}{*}{$<0.001$} \\
\hline NH Black & $9.6 \%$ & $7.0 \%$ & $10.0 \%$ & $13.3 \%$ & $15.8 \%$ & \\
\hline Hispanic & $1.2 \%$ & $2.6 \%$ & $2.6 \%$ & $2.3 \%$ & $15.5 \%$ & \\
\hline Other/unknown & $6.0 \%$ & $4.1 \%$ & $5.1 \%$ & $5.5 \%$ & $8.3 \%$ & \\
\hline Married & $61.7 \%$ & $61.8 \%$ & $63.7 \%$ & $65.1 \%$ & $61.5 \%$ & $<0.001$ \\
\hline \multicolumn{7}{|l|}{ Socioeconomic factors } \\
\hline \multicolumn{7}{|l|}{ Household income (1000 dollars) } \\
\hline$<\$ 20$ & $41.9 \%$ & $32.3 \%$ & $25.2 \%$ & $17.8 \%$ & $24.6 \%$ & \multirow[t]{5}{*}{$<0.001$} \\
\hline$\$ 20-\$ 35$ & $21.3 \%$ & $25.3 \%$ & $24.5 \%$ & $25.4 \%$ & $21.1 \%$ & \\
\hline$\$ 35-\$ 75$ & $14.4 \%$ & $16.9 \%$ & $22.8 \%$ & $24.1 \%$ & $24.8 \%$ & \\
\hline$\$ 75$ or more & $5.4 \%$ & $8.9 \%$ & $11.7 \%$ & $18.2 \%$ & $17.2 \%$ & \\
\hline Unknown & $17.0 \%$ & $16.7 \%$ & $15.8 \%$ & $14.6 \%$ & $12.3 \%$ & \\
\hline \multicolumn{7}{|l|}{ Educational attainment } \\
\hline Some high school or lower & $29.9 \%$ & $25.4 \%$ & $16.9 \%$ & $9.0 \%$ & $16.3 \%$ & \multirow[t]{4}{*}{$<0.001$} \\
\hline High school or GED & $38.2 \%$ & $39.0 \%$ & $40.9 \%$ & $38.6 \%$ & $31.8 \%$ & \\
\hline Some college & $21.0 \%$ & $23.3 \%$ & $24.6 \%$ & $27.3 \%$ & $26.7 \%$ & \\
\hline College or higher & $10.9 \%$ & $12.3 \%$ & $17.7 \%$ & $25.1 \%$ & $25.3 \%$ & \\
\hline $\begin{array}{l}\text { Employed/self-employed } \\
\text { Health factors }\end{array}$ & $19.7 \%$ & $27.9 \%$ & $31.4 \%$ & $37.7 \%$ & $36.2 \%$ & $<0.001$ \\
\hline \multicolumn{7}{|l|}{$\begin{array}{l}\text { Health factors } \\
\text { Body mass index }\left(\mathrm{kg} / \mathrm{m}^{2}\right)\end{array}$} \\
\hline$<25$ & $12.4 \%$ & $14.8 \%$ & $14.8 \%$ & $12.1 \%$ & $15.0 \%$ & \multirow[t]{4}{*}{$<0.001$} \\
\hline $25-29.9$ & $24.6 \%$ & $27.9 \%$ & $29.8 \%$ & $32.5 \%$ & $31.0 \%$ & \\
\hline 30 or higher & $59.2 \%$ & $53.0 \%$ & $50.9 \%$ & $50.4 \%$ & $49.8 \%$ & \\
\hline Unknown & $3.7 \%$ & $4.3 \%$ & $4.5 \%$ & $5.1 \%$ & $4.2 \%$ & \\
\hline \multicolumn{7}{|l|}{ Smoking } \\
\hline Never & $42.6 \%$ & $44.9 \%$ & $46.0 \%$ & $50.5 \%$ & $48.6 \%$ & \multirow{3}{*}{$<0.001$} \\
\hline Past & $35.2 \%$ & $34.7 \%$ & $36.2 \%$ & $37.4 \%$ & $36.2 \%$ & \\
\hline Current & $22.2 \%$ & $20.4 \%$ & $17.7 \%$ & $12.1 \%$ & $15.3 \%$ & \\
\hline Physical exercise & $50.0 \%$ & $55.2 \%$ & $57.5 \%$ & $57.4 \%$ & $61.8 \%$ & $<0.001$ \\
\hline Previous heart attack & $18.0 \%$ & $17.7 \%$ & $15.9 \%$ & $15.3 \%$ & $14.3 \%$ & $<0.001$ \\
\hline Coronary heart disease & $18.8 \%$ & $15.6 \%$ & $16.3 \%$ & $16.6 \%$ & $14.1 \%$ & $<0.001$ \\
\hline Stroke & $11.1 \%$ & $10.2 \%$ & $9.1 \%$ & $9.2 \%$ & $8.7 \%$ & $<0.001$ \\
\hline Disability & $48.4 \%$ & $45.6 \%$ & $42.6 \%$ & $35.8 \%$ & $38.4 \%$ & $<0.001$ \\
\hline Insulin use & $32.1 \%$ & $24.6 \%$ & $29.3 \%$ & $27.0 \%$ & $28.5 \%$ & $<0.001$ \\
\hline \multicolumn{7}{|l|}{ Diabetes duration, year } \\
\hline$<5$ & $28.1 \%$ & $33.5 \%$ & $26.6 \%$ & $30.7 \%$ & $28.1 \%$ & \multirow[t]{3}{*}{$<0.001$} \\
\hline $5-9$ & $24.7 \%$ & $23.1 \%$ & $25.0 \%$ & $24.5 \%$ & $25.7 \%$ & \\
\hline$\geq 10$ & $47.2 \%$ & $43.5 \%$ & $48.4 \%$ & $44.8 \%$ & $46.2 \%$ & \\
\hline \multicolumn{7}{|l|}{ Access to care factors } \\
\hline Has health insurance & $83.9 \%$ & $86.0 \%$ & $90.2 \%$ & $93.7 \%$ & $89.0 \%$ & $<0.001$ \\
\hline Has personal doctor & $91.2 \%$ & $91.9 \%$ & $95.1 \%$ & $95.6 \%$ & $92.5 \%$ & $<0.001$ \\
\hline Cost is a barrier & $24.0 \%$ & $21.9 \%$ & $15.5 \%$ & $11.4 \%$ & $16.3 \%$ & $<0.001$ \\
\hline Routine check-up, past 1 year & $83.9 \%$ & $86.8 \%$ & $88.0 \%$ & $86.9 \%$ & $84.8 \%$ & $<0.001$ \\
\hline Urban residence & $7.2 \%$ & $22.7 \%$ & $67.4 \%$ & $97.7 \%$ & $84.2 \%$ & $<0.001$ \\
\hline No MDs in county & $57.2 \%$ & $49.4 \%$ & $20.2 \%$ & $6.4 \%$ & $12.4 \%$ & $<0.001$ \\
\hline No podiatrist in county & $75.8 \%$ & $45.0 \%$ & $10.6 \%$ & $2.9 \%$ & $8.8 \%$ & $<0.001$ \\
\hline No eye doctor in county & $10.7 \%$ & $9.0 \%$ & $1.3 \%$ & $0.9 \%$ & $1.3 \%$ & $<0.001$ \\
\hline \multicolumn{7}{|l|}{ FQHCs in county } \\
\hline None & $26.0 \%$ & $34.7 \%$ & $33.2 \%$ & $9.5 \%$ & $18.4 \%$ & \multirow[t]{3}{*}{$<0.001$} \\
\hline 1 & $44.9 \%$ & $38.9 \%$ & $18.9 \%$ & $8.8 \%$ & $12.2 \%$ & \\
\hline 2 or more & $29.1 \%$ & $26.4 \%$ & $47.9 \%$ & $81.7 \%$ & $69.4 \%$ & \\
\hline
\end{tabular}


Table 1 Continued

\begin{tabular}{|c|c|c|c|c|c|c|}
\hline Respondent characteristics & Distressed & At-risk & Transitional & Competitive & Non-Appalachian & p Value \\
\hline \multicolumn{7}{|l|}{ HPSA designation, 2010} \\
\hline None & $9.8 \%$ & $25.8 \%$ & $18.5 \%$ & $9.9 \%$ & $11.2 \%$ & $<0.001$ \\
\hline Whole county & $46.9 \%$ & $29.6 \%$ & $31.6 \%$ & $43.5 \%$ & $45.9 \%$ & \\
\hline Part county & $43.3 \%$ & $44.5 \%$ & $50.0 \%$ & $46.6 \%$ & $42.9 \%$ & \\
\hline
\end{tabular}

*Numbers represent weighted percentages unless noted otherwise.

FQHC, federally qualified health centres; GED, general educational development; HPSA, health professional shortage area; NH, non-Hispanic.

race/ethnicity, sex and marital status were adjusted, differences between county economic levels within Appalachia in preventive care usage other than A1c tests, annual foot examination, annual eye examination and pneumococcal vaccination were not statistically significant any more. When the receipt of A1c tests were defined after excluding 'Don't know/Not sure' and 'Never heard of A1c test' answers, we found that the uptake of A1c tests was not different in distressed counties $(\mathrm{OR}=0.99 ; 95 \%$ CI 0.73 to 1.34$)$ but was significantly lower in at-risk counties $(\mathrm{OR}=0.77 ; 95 \%$ CI 0.59 to 0.99$)$ compared to competitive counties in the model adjusted for demographic factors.

When socioeconomic, health and access-to-care factors were further adjusted, disparities among Appalachian counties disappeared except for annual foot examination and pneumococcal vaccination. Compared to patients in competitive counties, those in distressed and at-risk counties were $26 \%(\mathrm{OR}=0.74 ; 95 \%$ CI 0.56 to 0.99$)$ and $41 \%(\mathrm{OR}=0.59 ; 95 \%$ CI 0.46 to 0.77 ) less likely to receive annual foot examinations, respectively. Patients in at-risk counties were $28 \%$ $(\mathrm{OR}=0.72 ; 95 \%$ CI 0.56 to 0.92$)$ less likely to receive pneumococcal vaccination compared to those in competitive counties.

Table 4 presents estimates for all covariates used in fully adjusted models for A1c test, foot examination and eye examination. We found that household income was significantly associated with annual receipt of eye examinations but not with A1c tests or foot examinations, while education was associated with foot and eye examinations. Neither was associated with annual uptake of two or more A1c tests. Access to care factors that were significantly associated with the uptake of these three services included health insurance, personal doctor, cost barrier and routine check-up in the past 12 months. Notably, respondents who had a routine check-up in the past 12 months also had $80-140 \%$ higher likelihood of meeting these recommendations than those who did not have one. In contrast, physicians per capita were not associated with the uptake of any of these services.

We conducted sensitivity analyses to test whether and how the availability of specialists such as podiatrists or eye doctors in county affected the receipt of annual foot or eye examinations. We found that adding one more eye doctor per 100000 population in county was associated with about $0.5 \%$ increase in the uptake of annual eye examinations (data not shown). We did not find any significant association between the number of podiatrists per capita and the uptake of annual foot examination. More importantly, however, inclusion of either of these variables in the models did not substantially change the relative differences in the uptake of annual foot or eye examinations between county economic levels.

Because Medicare covers these three services with $20 \%$ copayment and deductibles, we estimated the same regressions shown in table 4 using only respondents aged 65 or older to examine whether Medicare payment policy on diabetes preventive care affected uptake of these services. We found significant disparities for annual foot examination among respondents in at-risk counties (OR=0.60; 95\% CI 0.43 to 0.84 ) and for annual eye examination among those in distressed counties ( $\mathrm{OR}=0.56$; $95 \%$ CI 0.38 to 0.83$)$ compared to respondents in competitive counties (see online supplementary table A3). Interestingly enough, 'cost barrier' was associated with $25-35 \%$ lower uptake of these services among this Medicare population.

\section{CONCLUSIONS}

Our results show that there were significant disparities in the uptake of preventive care services that require visits to health professionals, including annual foot examination, annual eye examination, two or more Alc tests per year and pneumococcal vaccination in the less affluent (distressed and at-risk) counties compared to competitive counties in the Appalachian region. However, they were not different from or often exceeded competitive counties in terms of self-care practices such as daily blood glucose check or daily foot check. Non-Appalachian counties were not different from competitive counties, except for daily foot check and pneumococcal vaccination.

After the differences in demographic composition in age, sex, race/ethnicity and marital status was adjusted, differences in annual foot and eye examinations persisted with patients in less affluent (distressed or at-risk) counties significantly less likely to use these services. After socioeconomic, health and access-to-care factors were additionally adjusted, disparities between county economic levels disappeared in all recommendations, except for annual foot examinations whose disparities between county economic levels could not be adequately explained with factors available in this study. 


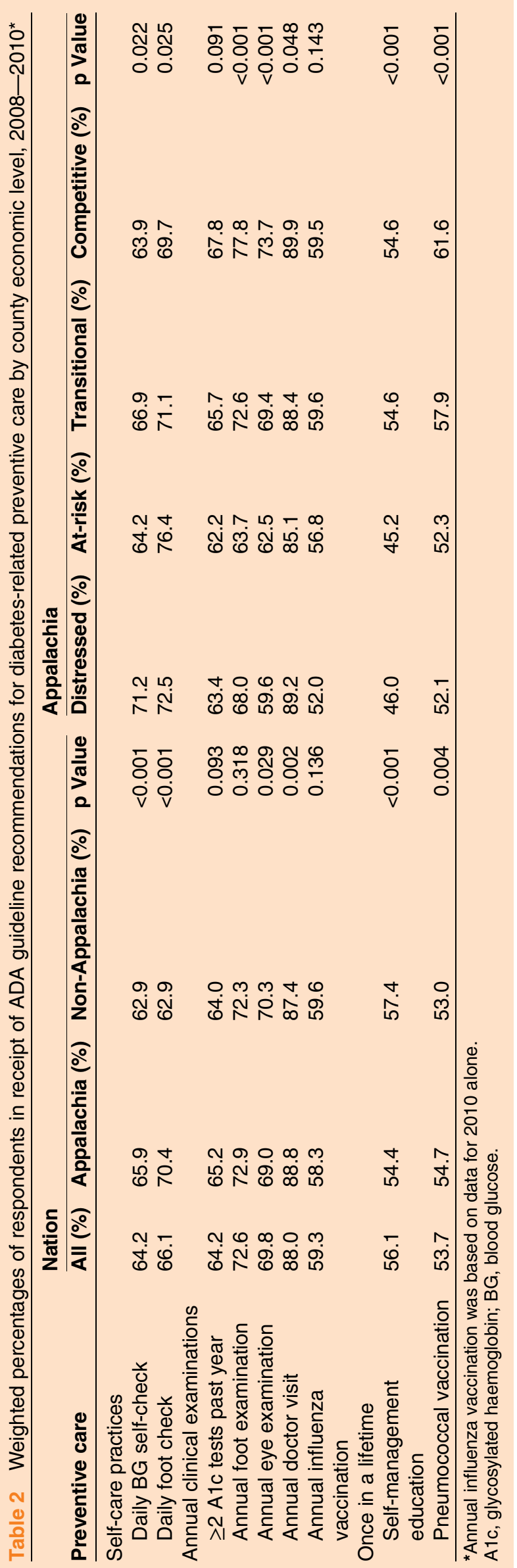

To the best of our knowledge, this is the first study that examined diabetes preventive care usage in the Appalachian region. This is an area that suffers from some of the most extreme geographic disparities in health outcomes in the United States. ${ }^{22} 29{ }^{30}$ Diabetes preventive care usage is especially important for patients in this region because of the higher prevalence of diabetes $^{24} 29$ and poorer access to healthcare ${ }^{20}$ compared to the rest of the country. Our results on self-care practices are not consistent with the 'fatalism' hypothesis that is often used as an explanation for health disparities for residents in the Appalachian region. ${ }^{31-34}$ Our data rather suggest that residents in the less affluent counties in Appalachia may have been practicing self-care as a compensatory behaviour for the lack of access to medical care.

A few previous studies examined disparities in the uptake of diabetes preventive care services. Persell $e t a l^{35}$ observed a graded relationship between age and the uptake of diabetes preventive services, except for annual foot examinations and A1c tests, using the 1999 BRFSS data. Our results based on 2008-2010 BRFSS are somewhat inconsistent with these earlier data in that the uptake of A1c tests, foot examinations and eye examinations all increased with age. Pu and Chewning ${ }^{36}$ reported significant racial/ethnic disparities in the use of these three services based on the 2008 Medical Expenditure Panel Survey. However, using BRFSS data for 2001-2010, Chen et al reported significantly better uptake of foot and eye examinations by non-Hispanic blacks compared to non-Hispanic whites during the 10-year period. In contrast, Hispanics had about 20\% lower uptake of Alc tests and foot examinations compared to non-Hispanic whites, but exceeded non-Hispanic whites in the uptake of eye examinations by about $15 \%$. Our study based on the same BRFSS data for 2008-2010 shows almost identical results to the Chen et al study.

Annual eye examination showed the largest disparities among county economic levels of all diabetes preventive services. Only about $60 \%$ and $63 \%$ took annual eye examinations in distressed and at-risk counties, respectively, compared to $74 \%$ in competitive counties. One of our notable findings is that the availability of eye doctors in county is significantly associated with the uptake of annual eye examinations. This can be explained by the fact that, unlike foot examinations that can be performed by any qualified health professionals, eye examinations tend to require visits to eye doctors such as ophthalmologists or optometrists who need to dilate pupils. This suggests that improving access is a key to reducing disparities in the uptake of annual eye examinations. Retinal photography performed by primary care physicians is recognised as an alternative to direct examination by the $\mathrm{ADA}^{12}$ and the American Academy of Ophthalmology ${ }^{37}$ and can be a viable option for improving the uptake of annual eye examinations for people residing in areas with poor access to eye specialists. Medicare currently reimburses only preventive eye 
Table 3 ORs (95\% Cls) for county economic levels in guideline-recommended preventive care receipt compared to competitive counties

\begin{tabular}{|c|c|c|c|c|c|}
\hline \multirow[b]{2}{*}{ Preventive care } & \multirow[b]{2}{*}{ Economic level } & \multicolumn{2}{|l|}{ Unadjusted } & \multicolumn{2}{|c|}{$\begin{array}{l}\text { Adjusted for demographic } \\
\text { factors }{ }^{\star}\end{array}$} \\
\hline & & OR (95\% Cl) & p Value & OR (95\% Cl) & p Value \\
\hline \multirow[t]{4}{*}{ Daily BG self-check } & Distressed & 1.399 (1.100 to 1.779$)$ & 0.006 & 1.115 (0.848 to 1.464$)$ & 0.436 \\
\hline & At-risk & 1.015 (0.818 to 1.260$)$ & 0.893 & 0.932 (0.739 to 1.176$)$ & 0.554 \\
\hline & Transitional & 1.145 (0.952 to 1.376$)$ & 0.151 & 1.019 (0.836 to 1.241$)$ & 0.855 \\
\hline & Non-Appalachian & 0.994 (0.836 to 1.180$)$ & 0.941 & 0.908 (0.755 to 1.092$)$ & 0.304 \\
\hline \multirow[t]{4}{*}{ Daily foot check } & Distressed & 1.145 (0.857 to 1.530$)$ & 0.360 & 1.105 (0.828 to 1.475$)$ & 0.497 \\
\hline & At-risk & $1.410(1.111$ to 1.791$)$ & 0.005 & 1.445 (1.129 to 1.849$)$ & 0.003 \\
\hline & Transitional & 1.072 (0.882 to 1.302$)$ & 0.486 & 1.061 (0.870 to 1.295$)$ & 0.557 \\
\hline & Non-Appalachian & 0.807 (0.673 to 0.968$)$ & 0.021 & 0.781 (0.649 to 0.939$)$ & 0.009 \\
\hline \multirow[t]{4}{*}{$\geq 2$ A1c tests past year } & Distressed & 0.707 (0.519 to 0.964$)$ & 0.029 & 0.660 (0.481 to 0.908$)$ & 0.011 \\
\hline & At-risk & 0.714 (0.542 to 0.940$)$ & 0.016 & 0.666 (0.503 to 0.881$)$ & 0.004 \\
\hline & Transitional & 0.803 (0.635 to 1.016$)$ & 0.067 & 0.760 (0.598 to 0.966$)$ & 0.025 \\
\hline & Non-Appalachian & 0.780 (0.626 to 0.971$)$ & 0.026 & 0.802 (0.641 to 1.003$)$ & 0.053 \\
\hline \multirow[t]{4}{*}{ Annual foot examination } & Distressed & 0.608 (0.465 to 0.796$)$ & $<0.000$ & 0.691 (0.521 to 0.918 ) & 0.011 \\
\hline & At-risk & $0.502(0.394$ to 0.641$)$ & $<0.000$ & 0.577 (0.449 to 0.741$)$ & $<0.000$ \\
\hline & Transitional & 0.756 (0.609 to 0.939$)$ & 0.011 & 0.780 (0.626 to 0.973$)$ & 0.028 \\
\hline & Non-Appalachian & 0.764 (0.622 to 0.938$)$ & 0.010 & 0.783 (0.636 to 0.965$)$ & 0.021 \\
\hline \multirow[t]{4}{*}{ Annual eye examination } & Distressed & 0.528 (0.408 to 0.684$)$ & $<0.000$ & $0.689(0.513$ to 0.925$)$ & 0.013 \\
\hline & At-risk & $0.596(0.472$ to 0.753$)$ & $<0.000$ & 0.726 (0.570 to 0.925$)$ & 0.009 \\
\hline & Transitional & 0.811 (0.659 to 0.999$)$ & 0.049 & $0.878(0.709$ to 1.085$)$ & 0.228 \\
\hline & Non-Appalachian & 0.837 (0.687 to 1.020$)$ & 0.078 & 0.863 (0.706 to 1.055$)$ & 0.150 \\
\hline \multirow[t]{4}{*}{ Annual doctor visit } & Distressed & 0.930 (0.614 to 1.407$)$ & 0.730 & 1.024 (0.648 to 1.617$)$ & 0.920 \\
\hline & At-risk & $0.646(0.455$ to 0.917$)$ & 0.015 & 6 to 1.060$)$ & 0.099 \\
\hline & Transitional & 0.856 (0.633 to 1.157$)$ & 0.312 & 0.885 (0.645 to 1.215$)$ & 0.450 \\
\hline & Non-Appalachian & 0.823 (0.620 to 1.092$)$ & 0.177 & 0.808 (0.600 to 1.090$)$ & 0.163 \\
\hline \multirow[t]{4}{*}{ Annual influenza vaccination } & Distressed & 0.738 (0.504 to 1.081$)$ & 0.119 & 1.001 (0.680 to 1.474$)$ & 0.996 \\
\hline & At-risk & 0.863 (0.618 to 1.205$)$ & 0.387 & 1.025 (0.727 to 1.445$)$ & 0.890 \\
\hline & Transitional & $1.009(0.760$ to 1.340$)$ & 0.951 & $1.056(0.791$ to 1.410$)$ & 0.713 \\
\hline & Non-Appalachian & 1.000 (0.768 to 1.302$)$ & 0.999 & 1.073 (0.821 to 1.403$)$ & 0.606 \\
\hline \multirow[t]{4}{*}{ Self-management education } & Distressed & 0.708 (0.558 to 0.897$)$ & 0.004 & 0.797 (0.609 to 1.042$)$ & 0.097 \\
\hline & At-risk & 0.684 (0.558 to 0.839$)$ & $<0.000$ & 0.814 (0.653 to 1.013$)$ & 0.065 \\
\hline & Transitional & $1.000(0.840$ to 1.191$)$ & 0.999 & 1.074 (0.893 to 1.292$)$ & 0.449 \\
\hline & Non-Appalachian & $1.093(0.928$ to 1.288$)$ & 0.288 & 1.105 (0.930 to 1.314$)$ & 0.257 \\
\hline \multirow[t]{4}{*}{ Pneumococcal vaccination } & Distressed & 0.675 (0.532 to 0.857$)$ & 0.001 & 0.677 (0.503 to 0.911$)$ & 0.010 \\
\hline & At-risk & 0.685 (0.553 to 0.848$)$ & 0.001 & 0.652 (0.514 to 0.828$)$ & $<0.000$ \\
\hline & Transition & 0.858 (0.711 to 1.035$)$ & 0.109 & 0.800 (0.650 to 0.986$)$ & 0.036 \\
\hline & Non-Appalachian & 0.710 (0.595 to 0.848$)$ & $<0.000$ & 0.777 (0.639 to 0.946$)$ & 0.012 \\
\hline
\end{tabular}

${ }^{*}$ Adjusted for age, sex, race/ethnicity and marital status.

examinations that include dilation of pupils by either ophthalmologists or optometrists.

Among the factors that affected preventive care usage, routine check-up in the past 12 months was one of the variables with the largest effect on preventive care use. Individuals with a routine check-up in the past 12 months were 1.8-2.4 times more likely to receive care consistent with guideline recommendations for annual foot and eye examinations and A1c tests. Individuals with an annual routine check-up may have better health behaviour and naturally have higher likelihood of following preventive care recommendations. Routine check-up may also have been a venue for patients to be informed of their annual preventive care needs among other things. This may suggest that, even for individuals who do not have routine check-ups, annual wellness visits
Medicare started to cover without copayment and deductibles since 2011 can be used to inform and activate patients regarding their diabetes preventive care recommendations.

Discrepancies in reported rates of A1c monitoring between poor and affluent counties were complicated by the increased 'Don't know/Not sure' and 'Never heard of A1c test' responses in distressed and at risk counties. These responses may illustrate the lower level of health literacy that likely parallels the education level for persons living in these counties. Inadequate evaluation for Alc and understanding of its significance is a substantial barrier for identifying the highest risk patients in this population.

Another noteworthy finding was that individuals who reported that cost was a barrier to medical care had 20- 
Table 4 Fully adjusted models for guideline-recommended care receipt for annual A1c test, annual foot examination and annual eye examination, all adults with diabetes in 2008-2010*

\begin{tabular}{|c|c|c|c|c|c|c|}
\hline \multirow[b]{2}{*}{ Variables } & \multicolumn{2}{|l|}{$\geq 2$ A1c tests last year } & \multicolumn{2}{|c|}{ Annual foot examination } & \multicolumn{2}{|l|}{ Annual eye examination } \\
\hline & OR (95\% Cl) & $\begin{array}{l}\mathbf{p} \\
\text { Value }\end{array}$ & OR $(95 \% \mathrm{Cl})$ & $\begin{array}{l}p \\
\text { Value }\end{array}$ & OR $(95 \% \mathrm{Cl})$ & $\begin{array}{l}\mathbf{p} \\
\text { Value }\end{array}$ \\
\hline \multicolumn{7}{|c|}{ County economic level [competitive] } \\
\hline Distressed & $1.046(0.789$ to 1.388$)$ & 0.755 & $0.740(0.556$ to 0.986$)$ & 0.040 & $0.784(0.580$ to 1.060$)$ & 0.114 \\
\hline At-risk & $0.974(0.766$ to 1.238$)$ & 0.827 & $0.592(0.457$ to 0.768$)$ & $<0.001$ & $0.791(0.618$ to 1.011$)$ & 0.061 \\
\hline Transitional & $0.957(0.782$ to 1.171$)$ & 0.668 & $0.768(0.615$ to 0.959$)$ & 0.020 & 0.889 (0.719 to 1.099$)$ & 0.277 \\
\hline Non-Appalachian & $0.920(0.761$ to 1.112$)$ & 0.390 & $0.798(0.648$ to 0.984$)$ & 0.035 & $0.893(0.732$ to 1.089$)$ & 0.264 \\
\hline Age, years & 0.995 (0.991 to 0.998$)$ & 0.001 & 1.004 (1.001 to 1.008$)$ & 0.019 & 1.020 (1.017 to 1.023$)$ & $<0.001$ \\
\hline Male & 0.917 (0.860 to 0.977$)$ & 0.007 & 1.114 (1.039 to 1.194$)$ & 0.002 & $0.934(0.872$ to 1.001$)$ & 0.054 \\
\hline \multicolumn{7}{|c|}{ Race/ethnicity [NH White] } \\
\hline $\mathrm{NH}$ Black & 0.831 (0.758 to 0.911$)$ & $<0.001$ & 1.416 (1.266 to 1.583$)$ & $<0.001$ & $1.238(1.119$ to 1.370$)$ & $<0.001$ \\
\hline Hispanic & 0.680 (0.585 to 0.791$)$ & $<0.001$ & 0.791 (0.675 to 0.927$)$ & 0.004 & $1.223(1.040$ to 1.439$)$ & 0.015 \\
\hline Other/unknown & 0.877 (0.776 to 0.991$)$ & 0.035 & 1.034 (0.892 to 1.198$)$ & 0.657 & $1.066(0.928$ to 1.224$)$ & 0.364 \\
\hline Married & 1.225 (1.148 to 1.307$)$ & $<0.001$ & 1.080 (1.003 to 1.164$)$ & 0.041 & 1.076 (1.003 to 1.154$)$ & 0.040 \\
\hline \multicolumn{7}{|c|}{ Household income $[<\$ 20$ 000] } \\
\hline$\$ 20000-\$ 34999$ & $1.019(0.932$ to 1.115$)$ & 0.677 & $0.943(0.856$ to 1.039$)$ & 0.236 & 1.117 (1.016 to 1.229$)$ & 0.022 \\
\hline$\$ 35000-\$ 74999$ & 1.147 (1.040 to 1.263$)$ & 0.006 & 0.959 (0.859 to 1.070$)$ & 0.450 & 1.170 (1.056 to 1.297$)$ & 0.003 \\
\hline$\geq \$ 75000$ & 1.281 (1.130 to 1.451$)$ & $<0.001$ & 0.960 (0.835 to 1.103$)$ & 0.561 & 1.215 (1.065 to 1.385$)$ & 0.004 \\
\hline Unknown & 0.844 (0.766 to 0.930$)$ & 0.001 & $0.860(0.770$ to 0.960$)$ & 0.007 & 1.120 (1.005 to 1.247$)$ & 0.040 \\
\hline \multicolumn{7}{|c|}{ Education [<some high school] } \\
\hline Some high school & 1.147 (0.977 to 1.347$)$ & 0.094 & 1.207 (1.020 to 1.429$)$ & 0.029 & 1.079 (0.907 to 1.285$)$ & 0.390 \\
\hline $\begin{array}{l}\text { High school } \\
\text { graduate or GED }\end{array}$ & $1.412(1.231$ to 1.619$)$ & $<0.001$ & 1.201 (1.042 to 1.384$)$ & 0.011 & 1.195 (1.031 to 1.385$)$ & 0.018 \\
\hline Some college & 7 (1.429 to 1.899$)$ & $<0.001$ & 1.275 (1.099 to 1.478$)$ & 0.001 & 1.258 (1.080 to 1.465$)$ & 0.003 \\
\hline $\begin{array}{l}\text { College graduate or } \\
\text { higher }\end{array}$ & 1.976 (1.698 to 2.299$)$ & $<0.001$ & $1.377(1.180$ to 1.608$)$ & $<0.001$ & 1.443 (1.228 to 1.695$)$ & $<0.001$ \\
\hline $\begin{array}{l}\text { Employed/ } \\
\text { self-employed } \\
\text { BMI }\left[<25 \mathrm{~kg} / \mathrm{m}^{2}\right]\end{array}$ & 0.996 (0.919 to 1.081$)$ & 0.929 & $1.017(0.933$ to 1.108$)$ & 0.705 & $0.933(0.859$ to 1.014$)$ & 0.101 \\
\hline $25-29.9 \mathrm{~kg} / \mathrm{m}^{2}$ & 1.179 (1.078 to 1.289$)$ & $<0.001$ & 1.215 (1.099 to 1.344$)$ & $<0.001$ & 1.049 (0.947 to 1.162$)$ & 0.357 \\
\hline$\geq 30 \mathrm{~kg} / \mathrm{m}^{2}$ & 1.280 (1.174 to 1.397$)$ & $<0.001$ & 1.324 (1.200 to 1.461$)$ & $<0.001$ & $0.992(0.901$ to 1.092$)$ & 0.874 \\
\hline Unknown & 1.185 (1.018 to 1.381$)$ & 0.029 & 1.225 (1.030 to 1.457$)$ & 0.022 & $1.010(0.860$ to 1.187$)$ & 0.901 \\
\hline \multicolumn{7}{|l|}{ Smoking [never] } \\
\hline Past & 1.066 (1.000 to 1.137$)$ & 0.049 & 0.947 (0.882 to 1.017$)$ & 0.131 & to 1.017 ) & 0.139 \\
\hline Current & 0.876 (0.797 to 0.963$)$ & 0.006 & 0.854 (0.771 to 0.946$)$ & 0.002 & 0.722 (0.655 to 0.796$)$ & 0.000 \\
\hline Exercise & 1.141 (1.072 to 1.215$)$ & $<0.001$ & 1.234 (1.152 to 1.321$)$ & $<0.001$ & 1.159 (1.084 to 1.239$)$ & $<0.001$ \\
\hline History of heart attack & 0.887 (0.806 to 0.976$)$ & 0.014 & $1.041(0.940$ to 1.153$)$ & 0.437 & 0.985 (0.888 to 1.094$)$ & 0.782 \\
\hline $\begin{array}{l}\text { Coronary heart } \\
\text { disease }\end{array}$ & $1.156(1.065$ to 1.255$)$ & 0.001 & 1.093 (0.999 to 1.196$)$ & 0.053 & $1.024(0.940$ to 1.117$)$ & 0.585 \\
\hline Stroke & 996) & 41 & 29) & 00 & $.188)$ & 0.181 \\
\hline Activity limitations & 1.218 (1.142 to 1.300$)$ & $<0.001$ & 1.095 (1.018 to 1.179$)$ & 0.015 & 0.937 (0.874 to 1.005$)$ & 0.070 \\
\hline Insulin user & 1.763 (1.634 to 1.903$)$ & $<0.001$ & 1.998 (1.836 to 2.174$)$ & $<0.001$ & 1.455 (1.343 to 1.576$)$ & $<0.001$ \\
\hline \multicolumn{7}{|c|}{ Diabetes duration $[<5$ years] } \\
\hline $5-9$ years & 1.384 (1.274 to 1.503$)$ & $<0.001$ & 1.326 (1.214 to 1.448$)$ & $<0.001$ & $1.146(1.0$ & 0.002 \\
\hline$\geq 10$ years & 1.591 (1.474 to 1.717$)$ & $<0.001$ & 1.646 (1.520 to 1.784$)$ & $<0.001$ & 1.462 (1.348 to 1.586$)$ & $<0.001$ \\
\hline Has health insurance & 1.378 (1.217 to 1.560$)$ & $<0.001$ & 1.343 (1.176 to 1.533$)$ & $<0.001$ & 1.625 (1.434 to 1.841$)$ & $<0.001$ \\
\hline Has personal doctor & 2.152 (1.842 to 2.513$)$ & $<0.001$ & $1.490(1.276$ to 1.740$)$ & $<0.001$ & 1.052 (0.896 to 1.235$)$ & 0.536 \\
\hline $\begin{array}{l}\text { Cost barrier to medical } \\
\text { Care }\end{array}$ & 0.759 (0.686 to 0.839$)$ & $<0.001$ & 0.797 (0.716 to 0.888$)$ & $<0.001$ & 0.683 (0.616 to 0.758$)$ & $<0.001$ \\
\hline $\begin{array}{l}\text { Routine check-up last } \\
12 \text { months }\end{array}$ & 1.852 (1.692 to 2.028$)$ & $<0.001$ & 2.390 (2.175 to 2.626$)$ & $<0.001$ & 1.822 (1.656 to 2.004$)$ & $<0.001$ \\
\hline Urban residence & $1.053(0.986$ to 1.124$)$ & 0.126 & $1.036(0.967$ to 1.111$)$ & 0.312 & 1.107 (1.033 to 1.185$)$ & 0.004 \\
\hline $\begin{array}{l}\text { Physicians per } \\
100000 \text { population in }\end{array}$ & 0.961 (0.888 to 1.040$)$ & 0.323 & 0.987 (0.971 to 1.003$)$ & 0.108 & 0.987 (0.969 to 1.004$)$ & 0.134 \\
\hline
\end{tabular}


Table 4 Continued

\begin{tabular}{|c|c|c|c|c|c|c|}
\hline \multirow[b]{2}{*}{ Variables } & \multicolumn{2}{|l|}{$\geq 2$ A1c tests last year } & \multicolumn{2}{|c|}{ Annual foot examination } & \multicolumn{2}{|l|}{ Annual eye examination } \\
\hline & OR (95\% Cl) & $\begin{array}{l}\mathbf{p} \\
\text { Value }\end{array}$ & OR $(95 \% \mathrm{Cl})$ & $\begin{array}{l}\mathbf{p} \\
\text { Value }\end{array}$ & OR $(95 \% \mathrm{CI})$ & $\begin{array}{l}\mathbf{p} \\
\text { Value }\end{array}$ \\
\hline \multicolumn{7}{|c|}{ FQHCs in county [none] } \\
\hline 1 & $1.068(0.973$ to 1.171$)$ & 0.166 & $1.049(0.952$ to 1.156$)$ & 0.330 & $0.990(0.901$ to 1.087$)$ & 0.826 \\
\hline 2 or more & 1.003 (0.926 to 1.086$)$ & 0.938 & $1.075(0.987$ to 1.171$)$ & 0.096 & 1.021 (0.940 to 1.108$)$ & 0.624 \\
\hline \multicolumn{7}{|c|}{ County HPSA designation [none] } \\
\hline Part county & $0.935(0.84$ & 0.199 & 0.977 (0.878 to 1.088$)$ & 0.678 & $0.900(0.8$ & 0.05 \\
\hline Whole county & 1.026 (0.930 to 1.133$)$ & 0.610 & 1.025 (0.924 to 1.138$)$ & 0.637 & $0.954(0.860$ to 1.060$)$ & 0.381 \\
\hline
\end{tabular}

${ }^{*}$ Reference categories are given in brackets.

BMI, body mass index; FQHC, federally qualified health centre; GED, general education development; HPSA, health professional shortage area; $\mathrm{NH}$, non-Hispanic.

$33 \%$ lower uptake of annual A1c tests, foot examinations and eye examinations compared to those who did not. This was also true of individuals aged $\geq 65$ years, which suggests that the $20 \%$ copayment itself may be a barrier. After the enactment of the Affordable Care Act, Medicare eliminated copayments for many preventive care services since 2011, but diabetes preventive services were not part of a long list of those services. Our findings on the cost barrier may suggest that Medicare coverage for diabetes preventive care services may need to be reconsidered.

Our results show that demographic and socioeconomic differences between the economic levels were able to account for most of the differences in diabetes preventive recommendations other than annual foot examinations, annual eye examinations (for the elderly) and pneumococcal vaccination. For example, geographic accessibility to healthcare is often recognised as a significant factor in health disparities in Appalachia, but we could not adjust for this and do not know whether the disparities in the uptake of these three services would disappear with improved access to care in the less affluent counties.

This study has several limitations to consider when interpreting our results. First, BRFSS data are selfreported and so the uptake of these services may be affected by recall bias or other forms of response bias, including social desirability. Second, we did not have a more direct measure of access to medical care such as geographic distance to the nearest healthcare facility or physician office. Our measures of access to care that include physicians or specialists per capita and FHQC's in county may not be specific enough for measuring access to care. Finally, as noted above, the coding of 'Don't know/Not sure' and 'Never heard of A1c test' responses may have led to some patients being incorrectly categorised as not having received Alc tests as recommended by the ADA guidelines. The higher rate of these responses in distressed and at risk counties may have confounded comparisons between groups.

In conclusion, we found significant disparities in the uptake of annual foot and eye examinations as well as annual A1c tests between county economic levels in
Appalachia, but no disparities in self-care practices such as daily A1c check or daily foot check. Improving access may reduce disparities in the uptake of annual eye examinations in Appalachia.

\section{Author affiliations}

${ }^{1}$ Department of Public Health Sciences, School of Medicine, University of Virginia, Charlottesville, Virginia, USA

${ }^{2}$ Department of Systems and Information Engineering, School of Engineering, University of Virginia, Charlottesville, Virginia, USA

${ }^{3}$ Department of Orthopaedic Surgery, School of Medicine, University of Virginia, Charlottesville, Virginia, USA

${ }^{4}$ Department of Ophthalmology, School of Medicine, University of Virginia, Charlottesville, Virginia, USA

${ }^{5}$ Department of Medicine, School of Medicine, University of Virginia,

Charlottesville, Virginia, USA

Acknowledgements The authors gratefully acknowledge the financial support from the Agency for Healthcare Research and Quality (R01HS018542).

Contributors M-WS derived the hypothesis, planned and supervised all analyses. M-WS and JL conducted analyses. M-WS wrote the manuscript. All authors participated in the interpretation of results and revision of the manuscript.

Disclaimer The paper presents the findings and conclusions of the authors; it does not necessarily represent the Agency for Healthcare Research and Quality. The corresponding author had full access to all of the data in the study and takes responsibility for the integrity of the data and the accuracy of the data analysis.

Funding Agency for Healthcare Research and Quality, R01HS018542.

Competing interests None declared.

Ethics approval This study was exempt from institutional review board approval because the BRFSS data were one of the approved public-use data sets.

Provenance and peer review Not commissioned; externally peer reviewed.

Data sharing statement No additional data are available.

Open Access This is an Open Access article distributed in accordance with the Creative Commons Attribution Non Commercial (CC BY-NC 4.0) license, which permits others to distribute, remix, adapt, build upon this work noncommercially, and license their derivative works on different terms, provided the original work is properly cited and the use is non-commercial. See: http:// creativecommons.org/licenses/by-nc/4.0/

\section{REFERENCES}

1. CDC. National Diabetes Statistics Report, 2014. Atlanta, GA National Center for Chronic Disease Prevention and Health Promotion, Center for Disease Control and Prevention, 2014. 
2. American Diabetes A. Economic costs of diabetes in the U.S. in 2012. Diabetes Care 2013;36:1033-46.

3. Centers for Medicare and Medicaid Services. Medicare Program; Voluntary Chronic Care Improvement under Traditional Fee-forService Medicare. Baltimore, MD: Centers for Medicare and Medicaid Services, 2004

4. Engelgau MM, Geiss LS, Saaddine JB, et al. The evolving diabetes burden in the United States. Ann Intern Med 2004;140:945-50.

5. Engelgau MM, Gregg EW. Tackling the global diabetes burden: will screening help? Lancet 2012;380:1716-18.

6. Cefalu WT, Petersen MP, Ratner RE. The alarming and rising costs of diabetes and prediabetes: a call for action! Diabetes Care 2014;37:3137-3138.

7. Zhuo X, Zhang P, Barker L, et al. The lifetime cost of diabetes and its implications for diabetes prevention. Diabetes Care 2014;37:2557-64.

8. Thorpe KE, Yang Z. Enrolling people with prediabetes ages 60-64 in a proven weight loss program could save Medicare $\$ 7$ billion or more. Health Aff (Millwood) 2011;30:1673-9.

9. Driver VR, Blume PA. Evaluation of wound care and health-care use costs in patients with diabetic foot ulcers treated with negative pressure wound therapy versus advanced moist wound therapy. J Am Podiatr Med Assoc 2014;104:147-53.

10. Zhuo X, Zhang P, Hoerger TJ. Lifetime direct medical costs of treating type 2 diabetes and diabetic complications. Am J Prev Med 2013:45:253-61.

11. Brandle M, Zhou H, Smith BR, et al. The direct medical cost of type 2 diabetes. Diabetes Care 2003;26:2300-4.

12. American Diabetes Association. Standards of Medical Care in Diabetes-2015. Diabetes Care 2015;38:S1-S87.

13. Kirkman MS, Briscoe VJ, Clark N, et al. Consensus development conference on $\mathrm{D}$, older $\mathrm{A}$ : diabetes in older adults: a consensus report. J Am Geriatr Soc 2012;60:2342-56.

14. Li R, Zhang P, Barker LE, et al. Cost-effectiveness of interventions to prevent and control diabetes mellitus: a systematic review. Diabetes Care 2010;33:1872-94.

15. Chen R, Cheadle A, Johnson D, et al. US trends in receipt of appropriate diabetes clinical and self-care from 2001 to 2010 and racial/ethnic disparities in care. Diabetes Educ 2014;40:756-66.

16. Bailey SR, O'Malley JP, Gold R, et al. Receipt of diabetes preventive services differs by insurance status at visit. Am J Prev Med 2015:48:229-33.

17. Brown DS, McBride TD. Impact of the Affordable Care Act on access to care for US adults with diabetes, 2011-2012. Prev Chronic Dis 2015;12:E64.

18. Ali MK, Bullard KM, Saaddine JB, et al. Achievement of goals in US diabetes care, 1999-2010. N Engl J Med 2013;368:

1613-24.

19. Behringer $\mathrm{B}$, Mabe $\mathrm{KH}$, Dorgan KA, et al. Local implementation of cancer control activities in rural Appalachia, 2006. Prev Chronic Dis 2009;6:A34

20. Halverson J, Ma L, Harner E. An analysis of disparities in health status and access to health care in the Appalachian region. Washington, DC: The Appalachian Regional Commission, 2004

21. Hutson SP, Dorgan KA, Phillips AN, et al. The mountains hold things in: the use of community research review work groups to address cancer disparities in Appalachia. Oncol Nurs Forum 2007;34:1133-9.

22. Anderson RT, Yang TC, Matthews SA, et al. Breast cancer screening, area deprivation, and later-stage breast cancer in Appalachia: does geography matter? Health Serv Res 2014;49:546-67.

23. Appalachian Regional Commission. Moving Appalachia forward: Appalachian regional commission strategic plan 2011-2016. Washington, DC: Appalachian Regional Commission, 2010.

24. Barker LE, Kirtland KA, Gregg EW, et al. Geographic distribution of diagnosed diabetes in the U.S.: a diabetes belt. Am J Prev Med 2011;40:434-9.

25. Center for Disease Control and Prevention. Age-adjusted percentage of adults aged 18 years or older with diagnosed diabetes receiving preventive care practices, United States, 2010. Atlanta, GA: National Center for Chronic Disease Prevention and Health Promotion, Center for Disease Control and Prevention, 2012. https://www.cdc.gov/diabetes/statistics/preventive/fAllPractices.htm (accessed 7 Oct 2015).

26. Source and methodology: distressed designation and county economic status classification system, FY 2007-FY 2016 [article online], 2015. http://www.arc.gov/research/Sourceand MethodologyCountyEconomicStatusFY2007FY2016.asp (accessed 7 Oct 2015)

27. Rao J. Small area estimation. Hoboken (NJ): John Wiley \& Sons, Inc, 2003.

28. Ashkenazy R, Abrahamson MJ. Medicare coverage for patients with diabetes. A national plan with individual consequences. $J$ Gen Intern Med 2006;21:386-92.

29. Barker L, Crespo R, Gerzoff RB, et al. Residence in a distressed county in Appalachia as a risk factor for diabetes, Behavioral Risk Factor Surveillance System, 2006-2007. Prev Chronic Dis 2010;7: A104.

30. Shrestha S, Kirtland K, Thompson T, et al. Spatial clusters of county-level diagnosed diabetes and associated risk factors in the United States. Open Diabetes J 2012;5:29-37.

31. Welch W. Self-control, fatalism, and health in Appalachia. $J$ Appalachian Stud 2011;17:108-22.

32. Vanderpool RC, Dressler EV, Stradtman LR, et al. Fatalistic beliefs and completion of the HPV vaccination series among a sample of young Appalachian Kentucky women. J Rural Health 2015;31:199-205.

33. Elam C. Culture, poverty and education in Appalachian Kentucky. Educ Culture 2002;18:10-13.

34. Drew EM, Schoenberg NE. Deconstructing fatalism: ethnographic perspectives on women's decision making about cancer prevention and treatment. Med Anthropol Q 2011;25: 164-82.

35. Persell SD, Zaslavsky AM, Weissman JS, et al. Age-related differences in preventive care among adults with diabetes. $A m$ J Med 2004;116:630-4.

36. Pu J, Chewning B. Racial difference in diabetes preventive care. Res Social Adm Pharm 2013;9:790-6.

37. American Academy of Ophthalmology. Preferred practice pattern guidelines: diabetic retinopathy. San Francisco (CA): American Academy of Ophthalmology, 2008. 